\title{
Research on the Control System of Horizontal Well Tractor Driving Motor
}

\author{
Jie Wang, Yongjun Chen*, Zhou He, Kuan Shi, Yinsheng Li \\ College of Electronics and Information, Yangtze University, Jingzhou, China \\ Email: *1257865132@qq.com
}

How to cite this paper: Wang, J., Chen, Y.J., He, Z., Shi, K. and Li, Y.S. (2020) Research on the Control System of Horizontal Well Tractor Driving Motor. Open Access Library Journal, 7: e6806.

https://doi.org/10.4236/oalib.1106806

Received: September 9, 2020

Accepted: October 6, 2020

Published: October 9, 2020

Copyright () 2020 by author(s) and Open Access Library Inc.

This work is licensed under the Creative Commons Attribution International License (CC BY 4.0).

http://creativecommons.org/licenses/by/4.0/ (c) (i) Open Access

\begin{abstract}
In recent years, the global demand for oil has been increasing. In order to reduce production costs, horizontal drilling technology is basically used for deep oil storage, so a cable-driven downhole towing system (horizontal well tractor) has emerged. The traditional horizontal well tractor drive motor has large volume, low efficiency, high vibration and noise, and cannot meet the requirements. Therefore, a permanent magnet synchronous motor with small size, light weight and high efficiency is proposed as the horizontal well drive motor. The paper discusses the coordinate transformation and mathematical model of permanent magnet synchronous motor, analyzes the working principle of permanent magnet synchronous motor vector control technology, and establishes a permanent magnet synchronous motor vector control simulation model using MATLAB simulation software. The simulation results verify that the control system has fast response speed and strong anti-interference, and meets the working requirements of horizontal well tractors.
\end{abstract}

\section{Subject Areas \\ Electric Engineering \\ Keywords \\ Horizontal Well Tractor, Permanent Magnet Synchronous Motor (PMSM), Vector Control}

\section{Introduction}

Due to the particularity of horizontal wells, the traditional technology of feeding downhole instruments through cable suspension by gravity cannot meet the requirements of feeding downhole instruments to the horizontal section of the ho- 
rizontal well. Therefore, a cable-driven downhole drag system (horizontal well traction system) is adopted. Device came into being [1]. The current driving motors used in oilfield tractors have the problems of large volume, low efficiency, high vibration and noise in actual working conditions [2]. In view of the above reasons, this paper proposes to use a high-efficiency permanent magnet synchronous motor (PMSM) as a horizontal well tractor drive motor [3]. Through the study of mathematical models and control systems, the dynamic performance of the system is improved.

Based on the analysis of the permanent magnet synchronous motor (PMSM) mathematical model and its vector control principle, the paper derives the transformation relationship between the three coordinate systems in PMSM vector control, and establishes the PMSM mathematical model in a two-phase synchronous rotating coordinate system. On this basis, the vector control principle of PMSM is analyzed, and the vector control strategy with $i_{d}=0$ is determined. The simulation of the permanent magnet synchronous motor control system is established using MATLAB software, and the simulation results and analysis are given. The results show that the control system has fast response speed, strong anti-interference, and meets the working requirements of horizontal well tractors.

\section{The Mathematical Model of Permanent Magnet Synchronous Motor}

\subsection{Coordinate System in Vector Control System}

When researching vector control algorithms, there are three common coordinate systems [4], as shown in Figure 1.

1) Three-phase stator coordinate system (ABC coordinate system)

The three-phase motor winding axes $\mathrm{A}, \mathrm{B}$, and $\mathrm{C}$ form a three-phase coordinate system of $A, B$, and $C$ with a mutual difference of $120^{\circ}$ electrical angles. The projection of any space vector on these three coordinate axes indicates the components of the vector on the three windings.

2) Two-phase stator coordinate system ( $\alpha$ - $\beta$ coordinate system)

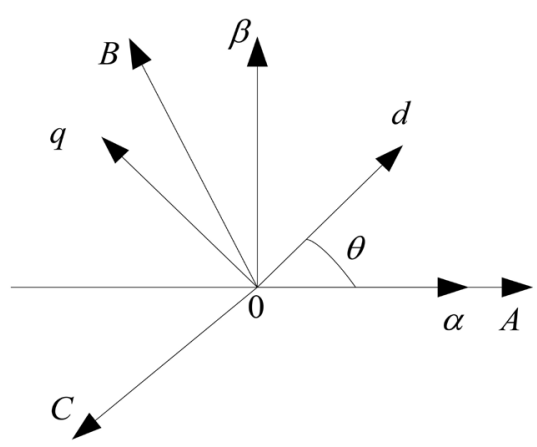

Figure 1. The relationship diagram of the three coordinate systems of the vector control system. 
The rotating magnetic field can also be generated when two-phase symmetrical current flows into two-phase symmetrical winding. Define the stationary two-phase coordinate system of the stator as the $\alpha-\beta$ coordinate system. The $\alpha$-axis coincides with the $A$-axis of the three-phase stator coordinate system, and the $\beta$-axis is $90^{\circ}$ ahead of the $\alpha$-axis in the counterclockwise direction, which is convenient for the mathematical description of the space vector.

3 ) Two-phase rotating coordinate system ( $d$ - $q$ coordinate system)

In the rotor coordinate system, $d$-axis is defined at the position of the rotor $N$-pole, and the $q$-axis is $90^{\circ}$ ahead of the $d$-axis. In space, the coordinate system and the rotor rotate at the same speed, so this coordinate system is also called the rotating coordinate system.

\subsection{Coordinate Transformation}

In order to simplify the three-phase system, it is necessary to transform the reference coordinate system of the motor. Replacing the original coordinate system with a new coordinate system is called coordinate transformation, which can change the complex relationship between variables in the original coordinate system into the simple relationship among variables in the new coordinate system.

Under the condition that the rotating magnetic field generated by the current before and after the transformation is equivalent and the motor power of the two systems remains unchanged before and after the transformation, the physical quantities of PMSM can be transformed between the three-phase stator coordinate system $\mathrm{ABC}$, the two-phase stator coordinate system and the two-phase rotating coordinate system [5].

1) Clark transform

The transformation of the vector from the original vector based on the three-phase stator coordinate system to the two-phase stator coordinate system is called Clark transformation. The principle diagram is shown in Figure 2.

The matrix form of Clark transformation is:

$$
\left[\begin{array}{l}
i_{\alpha} \\
i_{\beta}
\end{array}\right]=\sqrt{\frac{2}{3}}\left[\begin{array}{ccc}
1 & -\frac{1}{2} & -\frac{1}{2} \\
0 & \frac{\sqrt{3}}{2} & -\frac{\sqrt{3}}{2}
\end{array}\right]\left[\begin{array}{l}
i_{A} \\
i_{B} \\
i_{C}
\end{array}\right]
$$

Among them, $i_{A}, i_{B}, i_{C}$ is the current in the three-phase stator coordinate system; $i_{\alpha}, i_{\beta}$ is the current in the two-phase stator coordinate system.

2) Park transform

The purpose of Park transform is to convert two-phase alternating current into two-phase direct current. The principle is to rotate the stator two-phase coordinate system in the same plane with the same angular velocity of the rotation vector. At this time, the rotation vector can be regarded as a static DC component relative to the coordinate system, and these two components are called $d$ - $q$ components. The principle diagram is shown in Figure 3. 


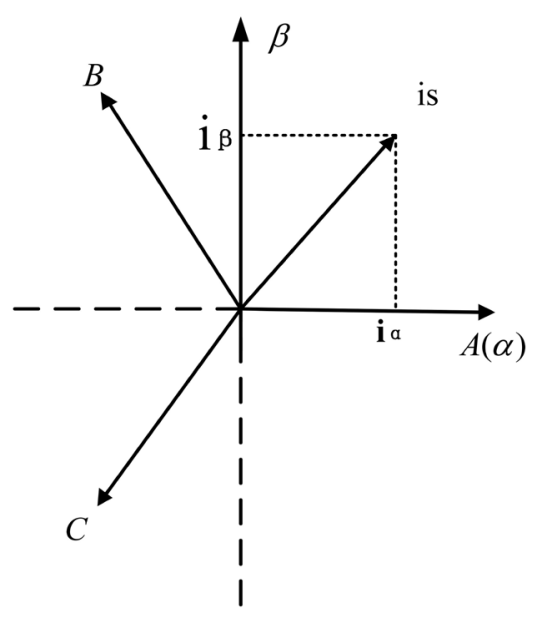

Figure 2. Clark transformation principle diagram.

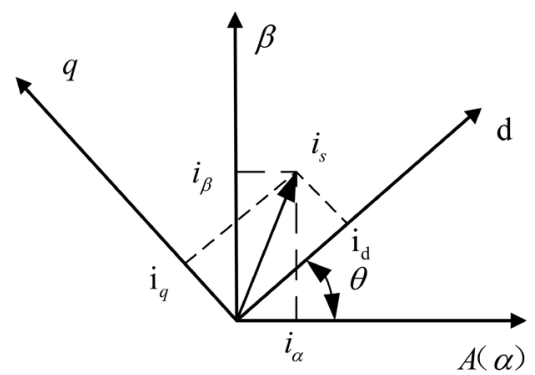

Figure 3. Park transformation principle diagram.

The matrix form of Park transformation is:

$$
\left[\begin{array}{l}
i_{d} \\
i_{q}
\end{array}\right]=\left[\begin{array}{cc}
\cos \theta & \sin \theta \\
-\sin \theta & \cos \theta
\end{array}\right]\left[\begin{array}{l}
i_{\alpha} \\
i_{\beta}
\end{array}\right]
$$

Among them, $i_{\alpha}, i_{\beta}$ is the current in the two-phase stator coordinate system, $i_{d}, i_{q}$ is the current in the two-phase rotating coordinate system.

\subsection{Mathematical Model in Two-Phase Rotating Coordinate System}

In order to simplify and solve the mathematical model equations, the basic equations of the three-phase stationary coordinate system of the PMSM stator are linearly transformed by using the coordinate transformation theory as shown in Figure 4 to realize the decoupling of the motor mathematical model. Among them, $u_{s}$ represents stator voltage, $i_{s}$ represents stator current, $\psi_{s}$ represents stator flux vector, $\psi_{f}$ represents rotor flux vector, $\theta$ represents rotor angular position and $\delta$ represents motor torque angle.

Ignoring the saturation of the motor core, ignoring the eddy current and hysteresis loss in the motor, and the rotor without damping winding, the mathematical model of PMSM in three-phase stator reference coordinate system can be expressed as follows:

Stator voltage equation: 


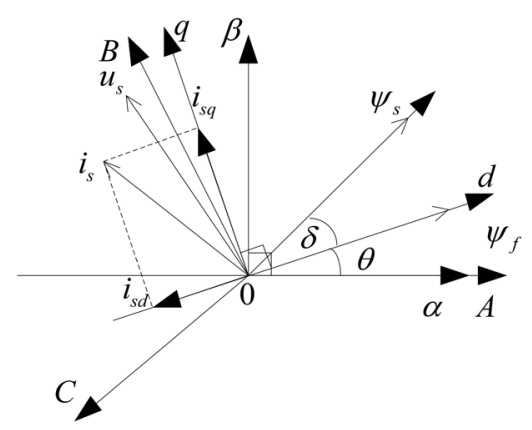

Figure 4. Permanent magnet synchronous motor stator three-phase static coordinate axis.

$$
u_{s}=R_{s} i_{s}+\frac{\mathrm{d} \psi_{s}}{\mathrm{~d} t}
$$

Stator flux equation:

$$
\psi_{s}=L_{s} i_{s}+\psi_{f} \mathrm{e}^{j \theta}
$$

Electromagnetic torque equation:

$$
T_{e}=\frac{3}{2} n_{p} \psi_{s} \times i_{s}
$$

The mathematical model of PMSM in the two-phase rotating coordinate system can be expressed as follows:

Stator voltage equation:

$$
\left\{\begin{array}{l}
u_{d}=R_{s} i_{d}+\frac{\mathrm{d} \psi_{d}}{\mathrm{~d} t}-\omega_{r} \psi_{q} \\
u_{q}=R_{s} i_{q}+\frac{\mathrm{d} \psi_{q}}{\mathrm{~d} t}+\omega_{r} \psi_{d}
\end{array}\right.
$$

Stator flux equation:

$$
\left\{\begin{array}{l}
\psi_{d}=L_{d} i_{d}+\psi_{f} \\
\psi_{q}=L_{q} i_{q}
\end{array}\right.
$$

Electromagnetic torque equation:

$$
T_{e}=\frac{3}{2} p_{n}\left(\psi_{d} i_{q}-\psi_{q} i_{d}\right)
$$

\section{Vector Control of Permanent Magnet Synchronous Motor}

Vector control, also known as magnetic field oriented control, is a technology of using frequency converter to control three-phase AC motor. The output of motor is controlled by adjusting the output frequency, output voltage and angle of frequency converter.

For permanent magnet synchronous motor, the commonly used vector control strategies are $i_{d}=0$ control, power factor $\cos \varphi=1$ control, constant flux linkage control, maximum torque/current control, flux weakening control, maximum output power control, etc. The paper adopts $i_{d}=0$ control. 
Substituting $i_{d}=0$ into the above formula (8), we can get:

$$
T_{e}=\frac{3}{2} p_{n} \psi_{d} i_{q}
$$

It can be known from the above formula that the electromagnetic torque of the motor is only determined by the $q$-axis current, which realizes the decoupling of the electromagnetic torque of the motor. Therefore, it can be seen that after adopting the control mode of $i_{d}=0$, the permanent magnet synchronous motor is equivalent to a separately excited DC motor. By controlling the current $i_{q}$, the electromagnetic torque can be controlled to realize the speed control. Figure 5 is the PMSM vector control principle diagram:

The read phase currents $i_{a}$ and $i_{b}$ can be converted into two-phase stationary coordinate systems $i_{\alpha}$ and $i_{\beta}$ by Clark transformation, and then combined with rotor position $\theta$, the current in the two-phase rotating coordinate system can be obtained. The speed and position sensor module compares the measured rotor angular velocity $\omega_{r}$ with the reference speed $\omega_{r}^{*}$, and generates the quadrature axis reference current through PI regulator. Compare $i_{d s}^{*}$ and $i_{q s}^{*}$ with the actual feedback $i_{d s}$ and $i_{q s}$, make the direct axis reference current $i_{d s}^{*}=0$, and convert it into voltage through PI regulator. Then combine the rotor angular position $\theta$ to perform inverse Park transformation and convert to a two-phase stationary coordinate system. The obtained voltage is converted into six switching signals by the PWM controller to control the turn-on and turn-off of the inverter to control the motor speed.

\section{PMSM Vector Control Simulation Model}

Build a simulation model in the MATLAB/Simulink environment, as shown in Figure 6.

In the simulation, the motor parameters are set as: the number of pole pairs $P_{n}=4$, the stator inductance $L_{d}=5.25 \mathrm{mH}, L_{q}=12 \mathrm{mH}$, the stator resistance $R=0.958 \Omega$. The simulation conditions are set as: DC side voltage $U_{d c}=311 \mathrm{~V}$, PWM switching frequency $f_{P W M}=10 \mathrm{kHz}$, sampling period $T_{S}=10 \mu \mathrm{s}$. The simulation results are shown in Figure 7.

In order to verify the correctness of the designed PI regulator parameters [6], the simulation conditions are set as: the reference speed is $N_{\text {ref }}=1000 \mathrm{r} / \mathrm{min}$, the load torque at the initial moment is $T_{L}=0 \mathrm{~N} \cdot \mathrm{m}$, when $t=0.2 \mathrm{~s}$ the load torque is $T_{L}=10 \mathrm{~N} \cdot \mathrm{m}$. The simulation results are shown in Figure 8, Figure 9.

From the above simulation, it can be seen that when the motor rises from zero speed to the reference speed of $1000 \mathrm{r} / \mathrm{min}$, although the motor speed is somewhat overmodulated at the beginning, it still has a relatively fast dynamic response speed. When the load increases suddenly, the motor can quickly recover to the given reference speed value, indicating that the designed PI regulator parameters have good dynamic performance and anti-interference ability, which can meet the actual motor control performance Demand. 


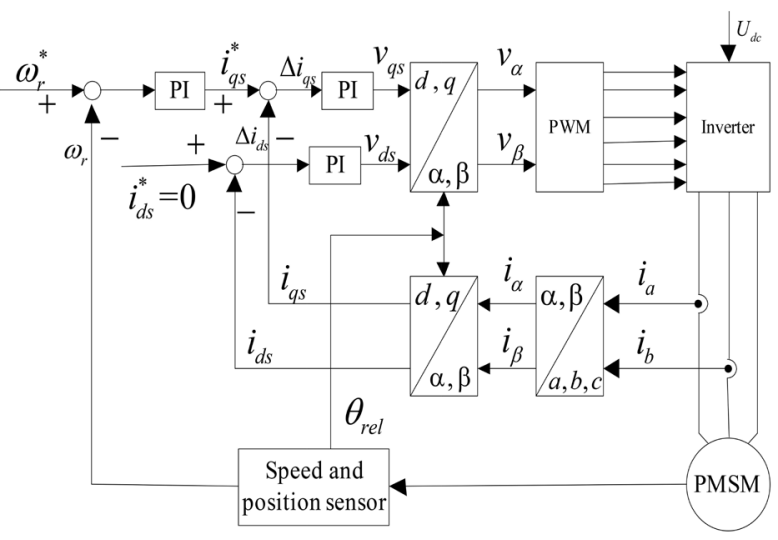

Figure 5. PMSM vector control principle diagram.

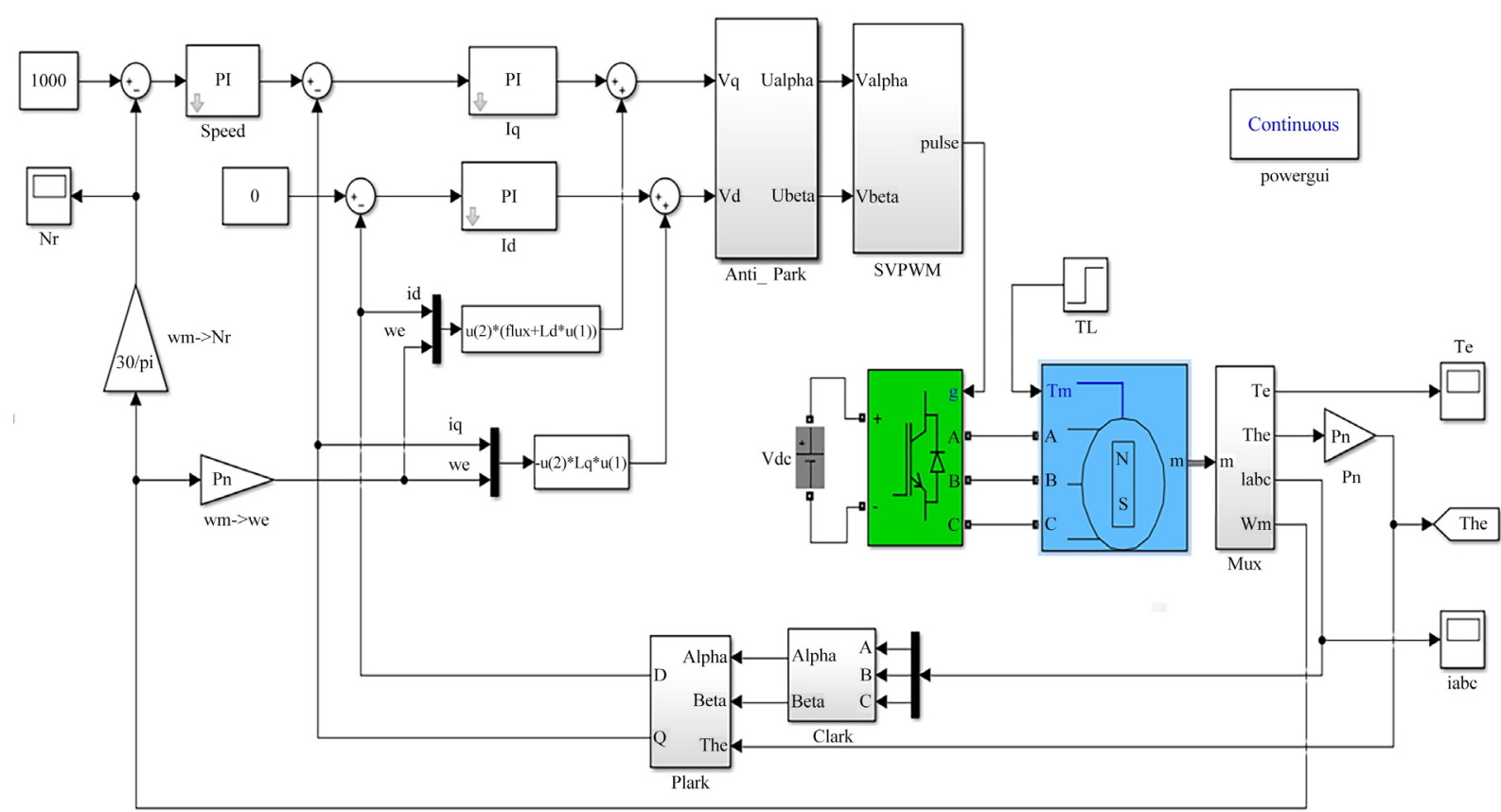

Figure 6. Vector control simulation model of permanent magnet synchronous motor.

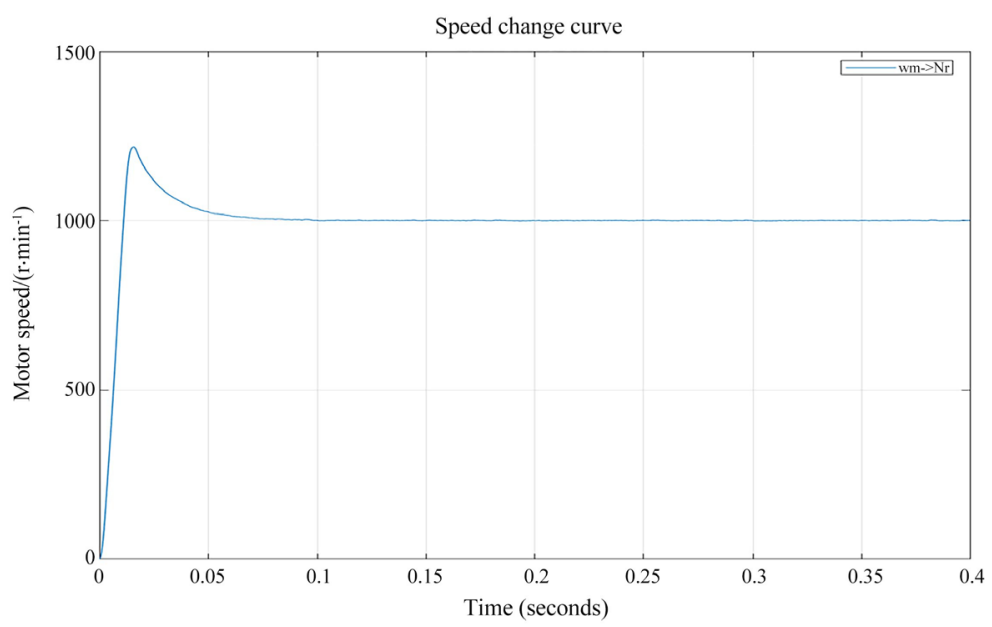

Figure 7. Speed change curve of $N_{r}$. 


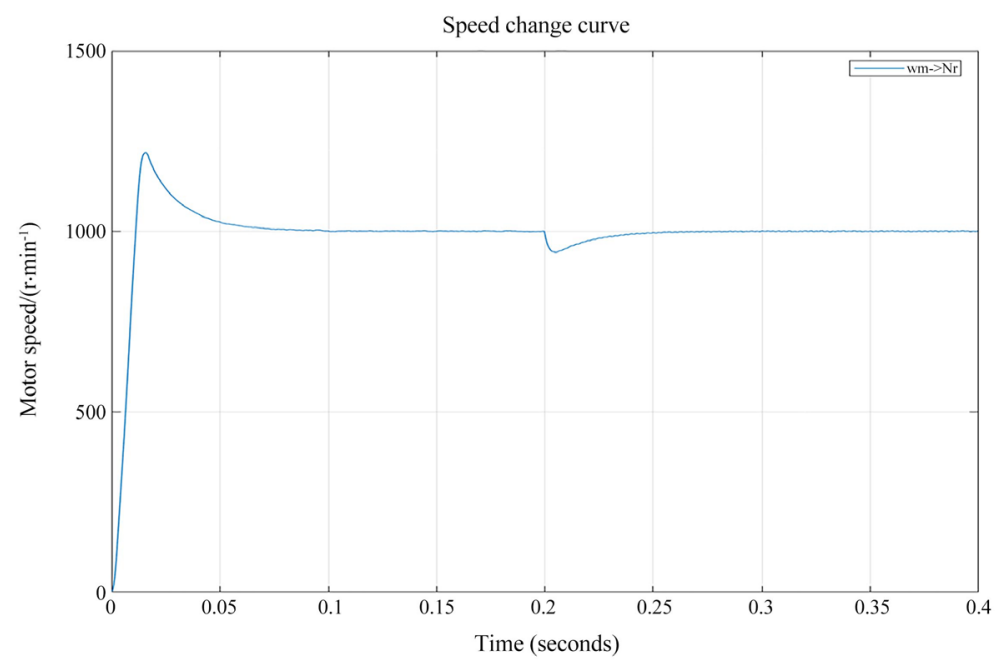

Figure 8. Motor speed diagram after disturbance.

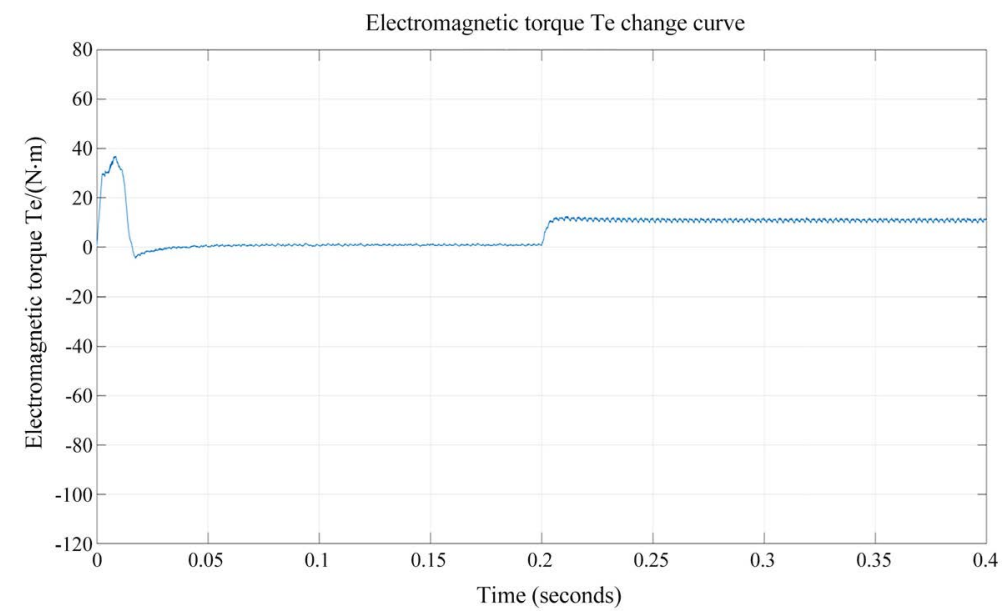

Figure 9. Electromagnetic torque $T_{e}$ change curve.

\section{Conclusion}

The simulation circuit of PMSM vector control system is established with MATLAB software, and the PMSM double closed-loop vector control system adopting $i_{d}=0$ control mode is realized. The simulation results show that the control system has strong anti-interference ability, fast response speed, small overshoot, and meets the actual working conditions of horizontal well tractors.

\section{Conflicts of Interest}

The authors declare no conflicts of interest regarding the publication of this paper.

\section{References}

[1] Li, X.X. (2019) Design and Analysis of Electric Drive Control System for Electric Drive Oil Drilling Rig. Chemical Enterprise Management, 14, 186-187.

[2] Hou, S.W. (2017) Research on Kinematics Simulation and Application of Horizon- 
tal Well Tractor. M.D. Thesis, Northeast Petroleum University, Daqing.

[3] Huang, J. (2014) Permanent Magnet Synchronous Motor Driver Design for Weft Feeder. M.D. Thesis, Soochow University, Suzhou.

[4] Liu, X.L. (2017) Research on Vector Control Theory, Simulation, Experiment and Application Based on Mathematical Model of PMSM. M.D. Thesis, Hefei University of Technology, Hefei.

[5] Yan, H., Tang, M.X. and Nie, Q.P. (2019) Research on Vector Control Simulation of Double Closed Loop Permanent Magnet Synchronous Motor. The World of Inverters, 5, 72-77.

[6] Dong, H., Wang, H. and Huang, K.Y. (2019) Design of PMSM Drive System Digital PI Adjuster Parameters. Electric Drive, 1, 7-10. 